\title{
Discontinuation of Scheduled Infliximab in Crohn's Patients With Clinical Remission: A Retrospective Single-Center Study
}

\author{
Huiqin $\mathrm{Hu}^{\mathrm{a}, \mathrm{c}}$, Cheng Xianga, c, Chen Qiu ${ }^{\mathrm{a}}$, Zhao Chenª, Silin Huang, \\ Li Liang ${ }^{\mathrm{b}}$, Xinying Wang, ${ }^{\mathrm{a}}$
}

\begin{abstract}
Background: It is crucial to determine whether infliximab (IFX) therapy could be safely interrupted in Crohn's disease (CD) patients with clinical remission. The outcome and risk predictors of relapse after IFX therapy stopped are controversial. The aim was to assess the relapse and predictive factors after IFX discontinuation in CD patients with clinical remission.
\end{abstract}

Methods: A retrospective cohort of $\mathrm{CD}$ patients with clinical remission who discontinued scheduled IFX therapy at Nanfang Hospital were included. The primary outcome was relapse. All patients were followed up for more than 3 months. Demographic, clinical, and laboratory parameters were evaluated for their predictive value of relapse.

Results: After a median follow-up period of 12.2(4.8 - 21.2) months, $55.7 \%(59 / 106)$ patients experienced a relapse. The cumulative relapse rate was $39 \%, 48 \%$ and $61 \%$ at 6 months, 1 year and 2 years, respectively. Based on multivariable analysis, $\mathrm{CD}$-related surgery before infusion ( $\mathrm{P}=0.013$, hazard ratio (HR): $2.671,95 \%$ confidential interval (CI): $1.230-5.798)$, step-up therapeutic regimen $(\mathrm{P}=0.035$, HR: $2.073,95 \% \mathrm{CI}$ : $1.054-4.080$ ), low albumin (Alb) level at week 0 (P = 0.022, HR: 3.431, 95\%CI: 1.196 - 9.846) and high C-reactive protein $(\mathrm{CRP})$ level at week $30(\mathrm{P}=0.007, \mathrm{HR}: 2.643,95 \% \mathrm{CI}: 1.310$ - 5.332) were associated with clinical relapse.

Conclusions: After cessation of scheduled IFX therapy in CD patients with clinical remission, nearly half of the patients experienced a relapse within 1 year. In the event of the presence of certain predictive factors, IFX scheduled therapy should probably be continued.

Keywords: Crohn's disease; Discontinuation of infliximab; Relapse; Risk factors

\footnotetext{
Manuscript accepted for publication February 03, 2017

${ }^{a}$ Guangdong Provincial Key Laboratory of Gastroenterology, Department of Gastroenterology, Nanfang Hospital, Southern Medical University, Guangzhou, China

bDepartmemt of Pathology, Southern Medical University, Guangzhou, China ${ }^{\mathrm{c}}$ These authors contributed equally to this work.

${ }^{\mathrm{d} C o r r e s p o n d i n g ~ A u t h o r: ~ X i n y i n g ~ W a n g, ~ D e p a r t m e n t ~ o f ~ G a s t r o e n t e r o l o g y, ~}$ Nanfang Hospital, Southern Medical University, Guangzhou 510515, China. Email: sunwingwxy@163.com
}

doi: https://doi.org/10.14740/gr800w

\section{Introduction}

Crohn's disease (CD) is a chronic relapsing inflammatory disorder of the gastrointestinal tract [1]. With the advent of tumor necrosis factor (TNF) antagonists, the concept of treating CD patients has substantially changed [2-4]. Infliximab (IFX), a chimeric (mouse/human) anti-TNF monoclonal antibody, has been proven superior to the conventional therapies for CD not only for remission induction but also for maintenance treatment $[5,6]$ and profoundly influences clinical practice.

The optimal therapeutic strategy for IFX use in treating $\mathrm{CD}$ is still debated despite more than a decade of clinical experience, such as the timing for starting IFX therapy, management of loss of response, treatment of recurrence [7, 8]. Another crucial issue is whether and when to stop biologic treatment in patients with remission [8-11]. In clinical settings, cessation of IFX therapy may be considered for various reasons including increased risks of infection and malignancies [12-14]. Moreover, the substantial cost of anti-TNF treatment imposes a great economic burden on CD patients. Consequently, most $\mathrm{CD}$ patients seem to require a suitable alternative long-term treatment strategy. This critical question has received attention in several clinical studies, but the populations and designs of these studies have differed, and the outcome after IFX therapy termination has been controversial [15-20]. Pariente and Laharie [10] suggested that patients should receive biologic treatment at least 1 year to minimize the relapse risk after TNF therapy withdrawal. Recent international guideline showed that there were no sufficient data available on the discontinuation of IFX therapy in CD patients and patients should be re-evaluated before IFX therapy was considered to be stopped [8].

The objective of the current study was to assess 1) the relapse rate of CD in Chinese patients with clinical remission on scheduled IFX therapy (about 8 months) discontinuation and 2) potential predictive factors associated with relapse.

\section{Patients and Methods}

\section{Study population}

Subjects were retrospectively identified from Nanfang Hospital of Southern Medical University between July 2010 and April 
2016. Eligible patients were those who were in clinical remission with scheduled IFX treatment for about 8 months, and then discontinued the agent based on physician global assessment. All patients were followed up for more than 3 months. Exclusion criteria were: 1) patients had previously biological therapy; 2) those performed gastrointestinal resection during IFX therapy; and 3) those had irregular maintenance infusions. The diagnosis of CD was based on routine endoscopic, radiological, histological and clinical criteria. Steroids were tapered off at the time of IFX initiation in patients who underwent a steroid treatment.

\section{Definitions}

Scheduled IFX infusions are commonly prescribed at $5 \mathrm{mg} /$ $\mathrm{kg}$ body weight with induction infusions at weeks 0,2 , and 6 , followed by maintenance therapy every 8 weeks. Clinical remission was defined as a Crohn's disease activity index [21] (CDAI) score of less than 150 points. Mucosal healing $(\mathrm{MH})$ was defined as a simple endoscopic score for Crohn's disease [22] (SES-CD) of less than 2. Clinical relapse was defined as retreatment with a biologic therapy or systemic steroid or CDrelated surgery. And endoscopic relapse was defined as SES$\mathrm{CD}>2$.

\section{Data collection}

CD patients who were treated with IFX (infusions at week 0,2 , and 6 , then followed by maintenance infusions every 8 weeks) and discontinued the drug after clinical remission were retrieved from an available IFX infusion database. Clinical and endoscopic data were later retrieved from patient medical records.

Clinical and demographic data at each time of hospital stay were collected, and CDAI score was calculated prior to each IFX infusion. An endoscopy was performed between the initial and the last IFX infusion, and SES-CD was calculated at the same time. Hemoglobin $(\mathrm{Hb})$, hematocrit (Hct), C-reactive protein (CRP) and serum albumin (Alb) levels were measured by routine procedures. Disease phenotypes of $\mathrm{CD}$ patients were determined according to the Montreal classification [23].

\section{Ethical consideration}

No application for ethnics committee was needed as this was a retrospective study, and the informed patient consent was obtained.

\section{Statistical analysis}

Descriptive statistics was expressed as percentages for discrete variables, and mean with standard deviation (SD) or median with quartiles for continuous variables, as appropriate. The rate of relapse was estimated by survival analysis. Variables

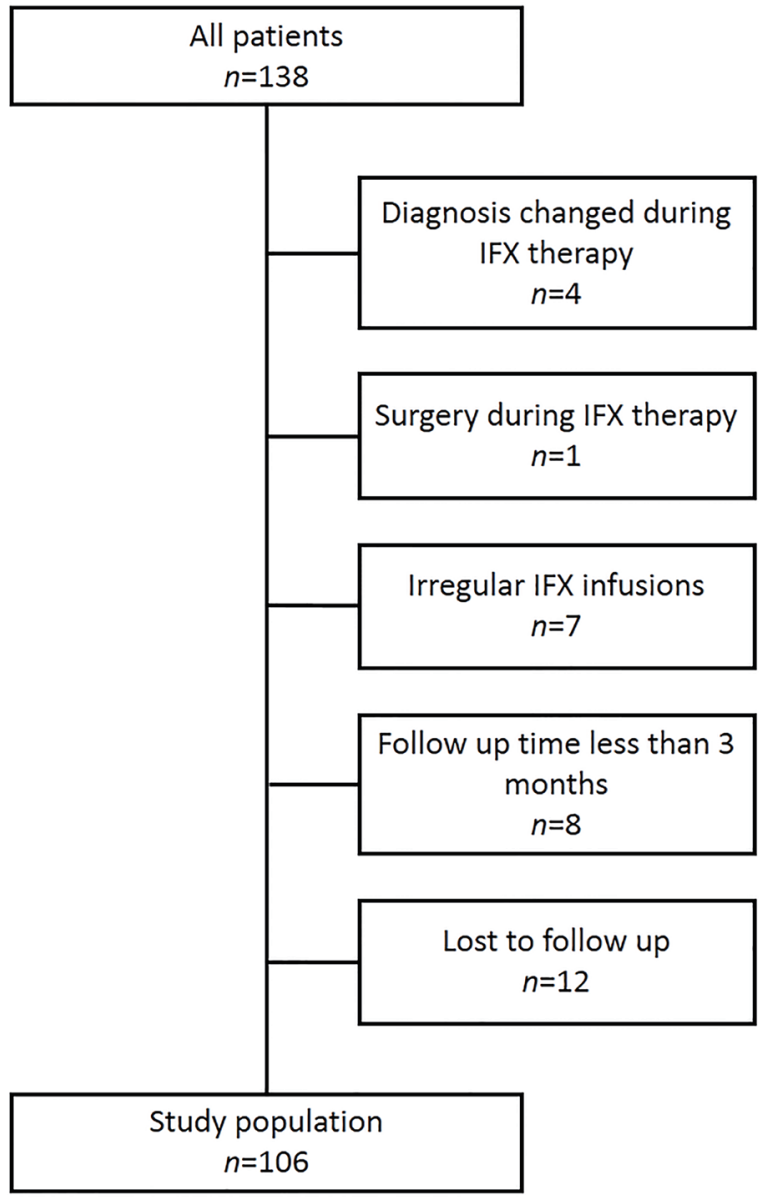

Figure 1. Study population. IFX: infliximab.

were initially assessed for association with relapse using univariate Cox proportional hazard regression analysis, and all variables with $\mathrm{P}<0.05$ on univariate analysis were included in a multivariable Cox model.

For statistical analysis, SPSS version 19.0 (IBM, Chicago, IL, USA) was used. P-values were two-sided, and $\mathrm{P}<0.05$ was considered significant.

\section{Results}

\section{Patient characteristics}

A total of $106 \mathrm{CD}$ patients (72 males and 34 females) treated with scheduled IFX infusions were included (Fig. 1). All patients discontinued IFX treatment after reaching a stable state of clinical remission. The demographic, clinical, biologic, and endoscopic characteristics of these patients are summarized in Table 1.

The median time of follow-up after IFX cessation was 12.2 months (4.8 - 21.2). The median CDAI was 213.5 (160.0 - 265.3) at the beginning of the treatment. Twenty-eight patients had perianal disease and 16 underwent perianal abscess 
Table 1. Characteristics of the Included Patients

\begin{tabular}{|c|c|}
\hline Characteristics & CD patients $(n=106)$ \\
\hline Male, n (\%) & $72(67.9)$ \\
\hline Active smoker, n (\%) & $3(2.8)$ \\
\hline Age (years) at diagnosis, mean (SD) & $26.6(9.5)$ \\
\hline \multicolumn{2}{|l|}{ Montreal classification } \\
\hline \multicolumn{2}{|l|}{ Age (years) at diagnosis, n (\%) } \\
\hline$\leq 16$ years $(\mathrm{A} 1)$ & $10(9.4)$ \\
\hline $17-40$ years (A2) & $83(78.3)$ \\
\hline$>40$ years $(\mathrm{A} 3)$ & $13(12.3)$ \\
\hline \multicolumn{2}{|l|}{ Disease site, $\mathrm{n}(\%)$} \\
\hline Ileum (L1) & $36(34.0)$ \\
\hline Colon (L2) & $7(6.6)$ \\
\hline Ileocolon (L3) & $63(59.4)$ \\
\hline \multicolumn{2}{|l|}{ Disease behavior, n (\%) } \\
\hline Inflammatory (B1) & $55(51.9)$ \\
\hline Stricturing (B2) & $41(38.7)$ \\
\hline Penetrating (B3) & $10(9.4)$ \\
\hline Perianal disease, $\mathrm{n}(\%)$ & $28(26.4)$ \\
\hline Extraintestinal manifestations, $\mathrm{n}(\%)$ & $10(9.4)$ \\
\hline \multicolumn{2}{|l|}{ Disease duration $(\mathrm{m}), \mathrm{n}(\%)$} \\
\hline$\leq 18$ & $84(79.2)$ \\
\hline$>18$ & $22(20.8)$ \\
\hline Gastrointestinal surgery before infusion, n (\%) & $27(25.5)$ \\
\hline \multicolumn{2}{|l|}{ Therapeutic regimen, $\mathrm{n}(\%)$} \\
\hline Step-up & $30(28.3)$ \\
\hline Top-down & $76(71.7)$ \\
\hline CRP level at week 0/30, median (IQR) & $9.9(3.0-38.9) / 1.49(0.48-6.11)$ \\
\hline Alb level at week 0/30, median (IQR) & $37.7(33.7-41.6) / 42.3(39.2-45.7)$ \\
\hline WBC level at week 0/30, median (IQR) & $7.12(5.91-8.92) / 5.57(4.83-6.58)$ \\
\hline $\mathrm{Hb}$ level at week 0/30, median (IQR) & $115.0(101.0-130.3) / 129.0(117.5-143.0)$ \\
\hline Hct level at week 0/30, median (IQR) & $36.6(32.7-40.5) / 39.3(35.9-43.2)$ \\
\hline CDAI at week 0/30, median (IQR) & $213.5(160.0-265.3) / 64.5(39.8-90.5)$ \\
\hline AZA at IFX discontinuation, $\mathrm{n}(\%)$ & $77(72.6)$ \\
\hline
\end{tabular}

CRP: C-reactive protein; Alb: albumin; WBC: white blood cell; Hb: hemoglobin; Hct: hematocrit; AZA: azathioprine; CDAl: Crohn's disease activity index; SD: standard deviation; IQR: interquartile range.

operation before recruitment. Twenty-seven of 106 patients underwent gastrointestinal surgery before the initial infusion. In addition, 77 of the 106 patients were followed with $2 \mathrm{mg} /$ $\mathrm{kg}$ azathioprine treatment. At the time of IFX discontinuation, 35 patients had an endoscopy and 28 of them achieved $\mathrm{MH}$.

\section{Outcome of IFX discontinuation}

At a median time of 12.2 months after cessation of IFX therapy, 59/106 patients (41 males and 18 females) experienced a relapse. Five of them underwent CD-related surgery, four patients received systemic steroid treatment, and 48 patients restarted IFX therapy.

Duration of clinical remission after discontinuation of IFX is shown in Figure 2. The cumulative probability of relapse after discontinuing IFX treatment was $39 \%, 48 \%$ and $61 \%$ at 6 months, 1 year and 2 years, respectively. Survival analysis revealed that almost half the patients continued to be in remission during the median follow-up period of 12.2 months. Finally, $37 \%$ of patients were in remission up to the end of follow-up after 4 years. 


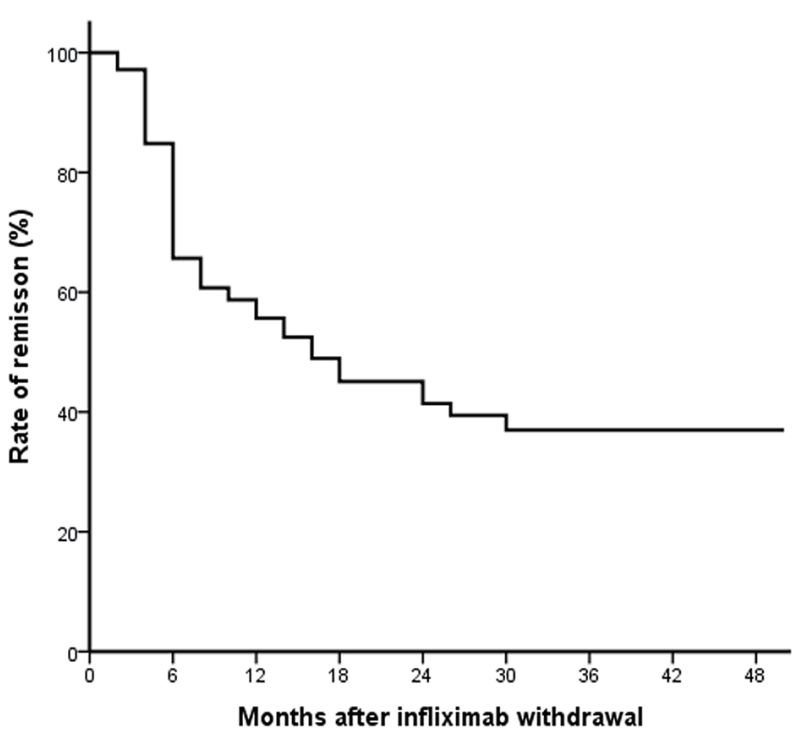

Figure 2. The rate of remission after infliximab withdrawal in patients with Crohn's disease.

\section{Factors associated with relapse}

In the univariate analysis, eight factors proved to be associated with relapse after IFX withdrawal (Table 2), including CDrelated surgery before IFX infusion $(P=0.049)$, step-up therapeutic regimen $(\mathrm{P}=0.027)$, low $\mathrm{Hb}$ level at week $0(\mathrm{P}=0.004)$, low Hct level at week $0(\mathrm{P}=0.020)$, low Alb level at week 0 $(\mathrm{P}=0.027)$, low Hct level at week $30(\mathrm{P}=0.009)$, high $\mathrm{CRP}$ level at week $30(\mathrm{P}=0.000)$, and low Alb level at week 30 (P $=0.000)$. No other predictive factors of relapse (gender, age at diagnosis, disease location, concomitant immunosuppressors, and disease duration) were identified.

In a multivariable Cox model, CD-related surgery before infusion ( $\mathrm{P}=0.013$, hazard ratio (HR): $2.671,95 \%$ confidential interval (CI): 1.230 - 5.798), step-up therapeutic regimen $(\mathrm{P}=0.035$, HR: 2.073, 95\%CI: 1.054 - 4.080), low Alb level at week $0(\mathrm{P}=0.022$, HR: 3.431, 95\%CI: $1.196-9.846)$ and high CRP level at week $30(\mathrm{P}=0.007, \mathrm{HR}: 2.643,95 \% \mathrm{CI}$ : 1.310 - 5.332) were associated with relapse in these CD patients (Table 3 ).

\section{Discussion}

A consensus regarding whether and when IFX can be discontinued safely in CD patients with IFX-induced remission is still lacking. The results of recent studies differed greatly on IFX treatment period and rates of relapse after IFX-induced remission. Several studies from Western countries reported that relapse rate 1 year after IFX withdrawal ranged from $36 \%$ to $44 \%[15-17,24,25]$. But the size of the cohorts was small, the IFX treatment period was various, and most of the patients were treated episodically. Scheduled maintenance therapy has been proven more effective than episodic therapy [26, 27], and our retrospective study assessed the relapse rate and predictors after scheduled IFX treatment in Chinese CD patients with a median follow-up of 12.2 months.

In China, there is a promotion strategy for IFX (two infusions of IFX were free if four infusions have been fully paid), so CD patients always stop IFX therapy after six infusions (almost 8-month therapy) as well as achieving a clinical remission. In our retrospective observational study, we analyzed $C D$ patients receiving six scheduled infusions of IFX, a relapse was observed in $48 \%$ of the patients after 1 year follow-up, which was similar to the previous studies and suggested nearly half of CD patients relapse within 1 year $[15,16,18]$. The cumulative relapse rate was $61 \%$ at 2 years, higher than that in a prospective observational study $(51 \%)$ [15]. A multidisciplinary European expert panel considered anti-TNF mono-therapy withdrawal appropriate in cases after 2 years of clinical and endoscopic remission, and after 4 years of clinical remission. In case of combined therapy, anti-TNF withdrawal, while continuing the impressive agents, was considered appropriate after 2 years of clinical remission [9]. Our data suggested that IFX withdrawal in CD patients who achieved clinical remission after 8 months IFX scheduled therapy was not appropriate when the patients had high risk factors.

Identification of a subgroup of patients with a low risk of relapse and validation of the relevant predictors are crucial for the cessation of IFX therapy. Several studies have reported various factors associated with recurrence, such as elevated CRP levels and fecal calprotecin, low Hb levels, dose intensification, long disease duration and the presence of mucosal damage $[15,28]$. But two observational studies could not identify any risk factor for relapse $[16,19]$. We also analyzed the predictors according to clinical and biochemical parameters. Consistent with these studies, our data also showed low Alb levels at week 0 and elevated CRP levels at week 30 were associated with relapse. CRP is an indicator of inflammation, and Alb levels reflect the overall nutritional status of the patients. Our results suggest that adequate Alb levels in the beginning and normalized CRP levels in the end period of scheduled IFX infusions are associated with low risk of post-IFX discontinuation relapse and IFX withdrawal may be considered in these patients.

Step-up therapeutic strategy was also associated with relapse. In an open randomized trial with $133 \mathrm{CD}$ patients, top-down therapeutic regimen proved to be better than conventional step-up regimen in reducing remission rate and $\mathrm{MH}$ [29]. In our study, about $70 \%$ patients received topdown strategy, with most of them within 1 year after diagnosis. The multivariable analysis revealed that the longterm remission rate of top-down group showed a significant improvement. Absence of previous surgery is considered favorable prognostic factor in CD. Our multivariable Cox model also revealed that previous CD-related surgery predicted an earlier recurrence. Interestingly, Louis et al [15] identified absence of previous surgical resection as a risk factor for relapse.

Moreover, with the introduction of biological therapies for IBD, the therapeutic target for $\mathrm{CD}$ has changed from clinical remission to $\mathrm{MH}$, even deep remission [30]. Even no consensus has been achieved in terms of defining MH and DR in IBD, 
Table 2. Univariate Analysis of Factors Associated With Relapse

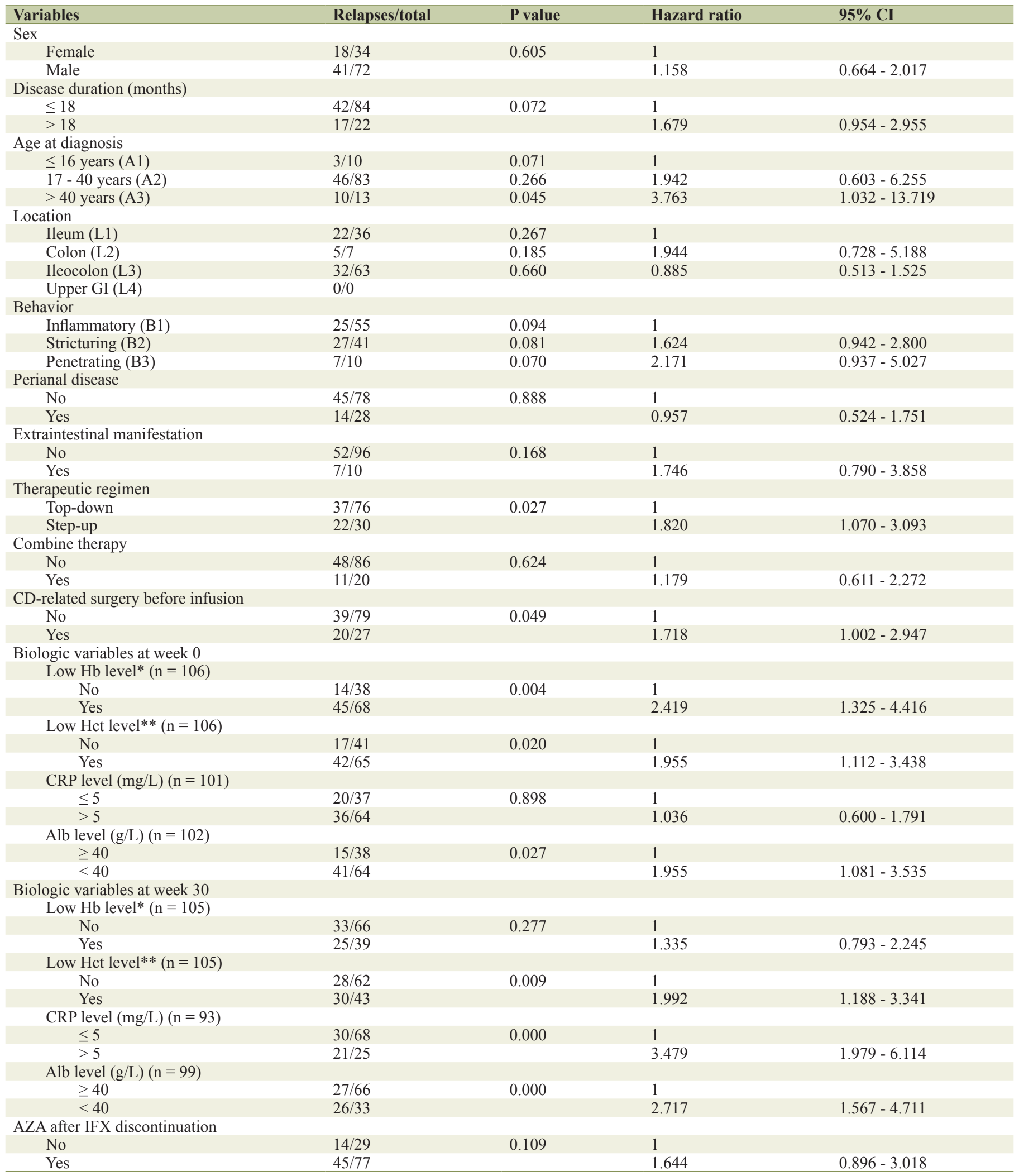

CRP: C-reactive protein; Alb: albumin; Hb: hemoglobin; AZA: azathioprine; Cl: confidence interval. *Male patients $<130 \mathrm{~g} / \mathrm{L}$, female patients $<115$ g/L. ${ }^{* *}$ Male patients $<0.4$, female patients $<0.35$. 
Table 3. Multivariable Cox Model

\begin{tabular}{llll}
\hline Variables & P value & Hazard ratio & 95\% CI \\
\hline CD-related surgery before infusion & 0.013 & 2.671 & $1.230-5.798$ \\
Step-up therapeutic regimen & 0.035 & 2.073 & $1.054-4.080$ \\
Low Hb level at week 0 & 0.116 & 2.183 & $0.825-5.779$ \\
Low Hct level at week 0 & 0.439 & 0.678 & $0.253-1.817$ \\
Low Alb level at week 0 & 0.022 & 3.431 & $1.196-9.846$ \\
Low Hct level at week 30 & 0.531 & 1.258 & $0.613-2.582$ \\
High CRP level at week 30 & 0.007 & 2.643 & $1.310-5.332$ \\
Low Alb level at week 30 & 0.819 & 0.916 & $0.434-1.935$ \\
\hline
\end{tabular}

After univariate analysis, variables with $\mathrm{P}<0.05$ were included in the multivariable Cox model. CRP: Creactive protein; Alb: albumin; $\mathrm{Cl}$ : confidence interval.

anti-TNF-induced $\mathrm{MH}$ and DR has been demonstrated to prolong remission and reduce rate of complications, hospitalizations and surgery $[26,27,31]$. A study suggested that $\mathrm{MH}$ as an endpoint is cost effective in CD patients [32]. In our study, only 35 patients performed an endoscopy and 80\% (28/35) achieved $\mathrm{MH}$ at the time of IFX discontinuation, and 10 of 28 relapsed during the follow-up period. On the contrary, a recent study showed survival of CD patients who were in deep remission (clinical and endoscopic healing; fecal calprotectin $<150 \mathrm{mg} / \mathrm{kg}$; CRP $\leq 5 \mathrm{mg} / \mathrm{L}$ ) was not better compared with those who did not fulfill these criteria [33]. Further prospective, case-control and large scale studies should be performed to identify predictors of sustained remission following withdrawal strategies in CD.

The present study has several limitations. First, endoscopy at the time of IFX initiation and withdraw was not performed in all patients, and endoscopic activity score was calculated by SES-CD, which could not assess the whole small intestine. Second, due to the constraints, fecal calprotectin, IFX trough levels and antibody status were not assessed in our study. Last, as the retrospective study, it is not available to assess the relapse rate according to risk strata. Even so, to our knowledge, this is the first study focusing on the cessation of IFX therapy after scheduled IFX treatment in Chinese CD patient group.

In conclusion, our study showed a relatively high rate of relapse in $\mathrm{CD}$ patients in 1 year after discontinuing the scheduled IFX therapy, especially those with high risks of relapse. Improving nutritional status, normalized CRP levels, and an early use of top-down strategy to avoid resection may help patients to have a better prognosis with sustained clinical remission.

\section{Grant Support}

This work was supported by grants from Science and Technology Planning Project of Guangdong Province (2014A020212172), Natural Science Foundation of Guangdong Province (2014A030313309), and Guangdong Provincial Bio-Engineering Research Center for Gastroenterology Diseases.

\section{Conflicts of Interest}

All authors declare that they have no relevant interests to disclose.

\section{References}

1. Cosnes J, Gower-Rousseau C, Seksik P, Cortot A. Epidemiology and natural history of inflammatory bowel diseases. Gastroenterology. 2011;140(6):1785-1794.

2. Rutgeerts P, D'Haens G, Targan S, Vasiliauskas E, Hanauer SB, Present DH, Mayer L, et al. Efficacy and safety of retreatment with anti-tumor necrosis factor antibody (infliximab) to maintain remission in Crohn's disease. Gastroenterology. 1999;117(4):761-769.

3. Hanauer SB, Feagan BG, Lichtenstein GR, Mayer LF, Schreiber S, Colombel JF, Rachmilewitz D, et al. Maintenance infliximab for Crohn's disease: the ACCENT I randomised trial. Lancet. 2002;359(9317):1541-1549.

4. Colombel JF, Sandborn WJ, Reinisch W, Mantzaris GJ, Kornbluth A, Rachmilewitz D, Lichtiger S, et al. Infliximab, azathioprine, or combination therapy for Crohn's disease. N Engl J Med. 2010;362(15):1383-1395.

5. Schnitzler F, Fidder H, Ferrante M, Noman M, Arijs I, Van Assche G, Hoffman I, et al. Long-term outcome of treatment with infliximab in 614 patients with Crohn's disease: results from a single-centre cohort. Gut. 2009;58(4):492500 .

6. Terdiman JP, Gruss CB, Heidelbaugh JJ, Sultan S, FalckYtter YT. American Gastroenterological Association Institute guideline on the use of thiopurines, methotrexate, and anti-TNF-alpha biologic drugs for the induction and maintenance of remission in inflammatory Crohn's disease. Gastroenterology. 2013;145(6):1459-1463.

7. Dignass A, Van Assche G, Lindsay JO, Lemann M, Soderholm J, Colombel JF, Danese S, et al. The second European evidence-based Consensus on the diagnosis and management of Crohn's disease: Current management. J Crohns Colitis. 2010;4(1):28-62.

8. D'Haens GR, Panaccione R, Higgins PD, Vermeire S, 
Gassull M, Chowers Y, Hanauer SB, et al. The London Position Statement of the World Congress of Gastroenterology on Biological Therapy for IBD with the European Crohn's and Colitis Organization: when to start, when to stop, which drug to choose, and how to predict response? Am J Gastroenterol. 2011;106(2):199-212; quiz 213.

9. Pittet V, Froehlich F, Maillard MH, Mottet C, Gonvers JJ, Felley C, Vader JP, et al. When do we dare to stop biological or immunomodulatory therapy for Crohn's disease? Results of a multidisciplinary European expert panel. J Crohns Colitis. 2013;7(10):820-826.

10. Pariente B, Laharie D. Review article: why, when and how to de-escalate therapy in inflammatory bowel diseases. Aliment Pharmacol Ther. 2014;40(4):338-353.

11. Sorrentino D, Nash P, Viladomiu M, Hontecillas R, Bassaganya-Riera J. Stopping anti-TNF agents in patients with Crohn's disease in remission: is it a feasible longterm strategy? Inflamm Bowel Dis. 2014;20(4):757-766.

12. Lichtenstein GR, Feagan BG, Cohen RD, Salzberg BA, Diamond RH, Price S, Langholff W, et al. Serious infection and mortality in patients with Crohn's disease: more than 5 years of follow-up in the TREAT registry. Am J Gastroenterol. 2012;107(9):1409-1422.

13. Ford AC, Peyrin-Biroulet L. Opportunistic infections with anti-tumor necrosis factor-alpha therapy in inflammatory bowel disease: meta-analysis of randomized controlled trials. Am J Gastroenterol. 2013;108(8):1268-1276.

14. Deepak P, Sifuentes H, Sherid M, Stobaugh D, Sadozai Y, Ehrenpreis ED. T-cell non-Hodgkin's lymphomas reported to the FDA AERS with tumor necrosis factor-alpha (TNF-alpha) inhibitors: results of the REFURBISH study. Am J Gastroenterol. 2013;108(1):99-105.

15. Louis E, Mary JY, Vernier-Massouille G, Grimaud JC, Bouhnik Y, Laharie D, Dupas JL, et al. Maintenance of remission among patients with Crohn's disease on antimetabolite therapy after infliximab therapy is stopped. Gastroenterology. 2012;142(1):63-70 e65; quiz e31.

16. Waugh AW, Garg S, Matic K, Gramlich L, Wong C, Sadowski DC, Millan M, et al. Maintenance of clinical benefit in Crohn's disease patients after discontinuation of infliximab: long-term follow-up of a single centre cohort. Aliment Pharmacol Ther. 2010;32(9):1129-1134.

17. Steenholdt C, Molazahi A, Ainsworth MA, Brynskov J, Ostergaard Thomsen O, Seidelin JB. Outcome after discontinuation of infliximab in patients with inflammatory bowel disease in clinical remission: an observational Danish single center study. Scand J Gastroenterol. 2012;47(5):518-527.

18. Molnar T, Lakatos PL, Farkas K, Nagy F, Szepes Z, Miheller P, Horvath G, et al. Predictors of relapse in patients with Crohn's disease in remission after 1 year of biological therapy. Aliment Pharmacol Ther. 2013;37(2):225233.

19. Molander P, Farkkila M, Salminen K, Kemppainen H, Blomster T, Koskela R, Jussila A, et al. Outcome after discontinuation of TNFalpha-blocking therapy in patients with inflammatory bowel disease in deep remission. Inflamm Bowel Dis. 2014;20(6):1021-1028.

20. Baert F, Moortgat L, Van Assche G, Caenepeel P, Vergau- we P, De Vos M, Stokkers P, et al. Mucosal healing predicts sustained clinical remission in patients with early-stage Crohn's disease. Gastroenterology. 2010;138(2):463-468; quiz e410-461.

21. Best WR, Becktel JM, Singleton JW, Kern F, Jr. Development of a Crohn's disease activity index. National Cooperative Crohn's Disease Study. Gastroenterology. 1976;70(3):439-444.

22. Daperno M, D'Haens G, Van Assche G, Baert F, Bulois P, Maunoury V, Sostegni R, et al. Development and validation of a new, simplified endoscopic activity score for Crohn's disease: the SES-CD. Gastrointest Endosc. 2004;60(4):505-512.

23. Silverberg MS, Satsangi J, Ahmad T, Arnott ID, Bernstein CN, Brant SR, Caprilli R, et al. Toward an integrated clinical, molecular and serological classification of inflammatory bowel disease: report of a Working Party of the 2005 Montreal World Congress of Gastroenterology. Can J Gastroenterol. 2005;19(Suppl A):5A-36A.

24. Papamichael K, Vande Casteele N, Gils A, Tops S, Hauenstein S, Singh S, Princen F, et al. Long-term outcome of patients with Crohn's disease who discontinued infliximab therapy upon clinical remission. Clin Gastroenterol Hepatol. 2015;13(6):1103-1110.

25. Brooks AJ, Sebastian S, Cross SS, Robinson K, Warren L, Wright A, Marsh AM, et al. Outcome of elective withdrawal of anti-tumour necrosis factor-alpha therapy in patients with Crohn's disease in established remission. J Crohns Colitis. 2015.

26. Rutgeerts P, Feagan BG, Lichtenstein GR, Mayer LF, Schreiber S, Colombel JF, Rachmilewitz D, et al. Comparison of scheduled and episodic treatment strategies of infliximab in Crohn's disease. Gastroenterology. 2004;126(2):402-413.

27. Rutgeerts P, Diamond RH, Bala M, Olson A, Lichtenstein GR, Bao W, Patel K, et al. Scheduled maintenance treatment with infliximab is superior to episodic treatment for the healing of mucosal ulceration associated with Crohn's disease. Gastrointest Endosc. 2006;63(3):433-442; quiz 464.

28. Gisbert JP, Marin AC, Chaparro M. Systematic review: factors associated with relapse of inflammatory bowel disease after discontinuation of anti-TNF therapy. Aliment Pharmacol Ther. 2015;42(4):391-405.

29. D'Haens G, Baert F, van Assche G, Caenepeel P, Vergauwe P, Tuynman H, De Vos M, et al. Early combined immunosuppression or conventional management in patients with newly diagnosed Crohn's disease: an open randomised trial. Lancet. 2008;371(9613):660-667.

30. Onal IK, Beyazit Y, Altinbas A, Kurt M, Arhan M. Maintenance therapy for Crohn's disease: should it be indefinite? Eur J Gastroenterol Hepatol. 2015;27(10):11151125 .

31. Schnitzler F, Fidder H, Ferrante M, Noman M, Arijs I, Van Assche G, Hoffman I, et al. Mucosal healing predicts long-term outcome of maintenance therapy with infliximab in Crohn's disease. Inflamm Bowel Dis. 2009;15(9):1295-1301.

32. Ananthakrishnan AN, Korzenik JR, Hur C. Can mucosal 
healing be a cost-effective endpoint for biologic therapy in Crohn's disease? A decision analysis. Inflamm Bowel Dis. 2013;19(1):37-44.

33. Bortlik M, Duricova D, Machkova N, Hruba V, Lukas
M, Mitrova K, Romanko I, et al. Discontinuation of antitumor necrosis factor therapy in inflammatory bowel disease patients: a prospective observation. Scand J Gastroenterol. 2016;51(2):196-202. 